\title{
LETTER
}

\section{Pulse pressure variation, stroke volume variation and dynamic arterial elastance}

\author{
Raphael Giraud, Nils Siegenthaler and Karim Bendjelid* \\ See related research by Monge Garcia et al., http://ccforum.com/content/15/1/R15
}

We read with interest the recent article by Monge Garcia and colleagues [1]. We have two comments regarding this interesting physiological study.

First, although we support their observation [2], their explanations may lead to some confusion. Indeed, the Edwards Vigileo ${ }^{\mathrm{TM}}$ system-FloTrac ${ }^{\mathrm{TM}}$ sensor calculates stroke volume (SV) using the equation:

$$
\mathrm{SV}=\mathrm{Khi} \times \sigma \mathrm{AP}
$$

where $\sigma \mathrm{AP}$ is the standard deviation of the arterial pressure (AP) curve and Khi a constant quantifying arterial elastance and vascular resistance [3]. As stroke volume variation (SVV):

$$
\begin{aligned}
& \mathrm{SVV}(\text { in } \%)=\left(\mathrm{SV}_{\text {max }}-\mathrm{SV}_{\text {min }}\right) / \mathrm{SV}_{\text {mean }} \\
& \operatorname{SVV}(\%)=\left(\mathrm{Khi} \times \sigma \mathrm{AP}_{\text {max }}-\mathrm{Khi} \times \sigma \mathrm{AP}_{\text {min }}\right) / \mathrm{Khi} \times \sigma \mathrm{AP}_{\text {mean }} \\
& \operatorname{SVV}(\%)=\mathrm{Khi} \times\left(\sigma \mathrm{AP}_{\text {max }}-\sigma \mathrm{AP}_{\text {min }}\right) / \mathrm{Khi} \times \sigma \mathrm{AP}_{\text {mean }} \\
& \operatorname{SVV}(\%)=\left(\sigma \mathrm{AP}_{\text {max }}-\sigma \mathrm{AP}_{\text {min }}\right) / \sigma \mathrm{AP}_{\text {mean }} \\
& \mathrm{SVV}(\%) \approx\left(\mathrm{PP}_{\text {max }}-\mathrm{PP}_{\text {min }}\right) / \mathrm{PP}_{\text {mean }}
\end{aligned}
$$

Which means that SVV $(\%) \approx$ pulse pressure variation (PPV; \%) for FloTrac ${ }^{\mathrm{TM}}$.

With the present mathematical equation, it can be demonstrated that the SVV calculated by FloTrac $^{\mathrm{TM}}$ $\left(\mathrm{SVV}_{\mathrm{FT}}\right)$ is not influenced by Khi, which means that $\mathrm{SVV}_{\mathrm{FT}}$ calculation does not include effective arterial elastance (Ea). The originality of Garcia and colleagues' finding is that they realized that when measuring PPV conventionally [4], the ratio $\mathrm{PPV} / \mathrm{SVV}_{\mathrm{FT}}$ becomes a mirror of a dynamic Ea, as the conventional PPV selected integrates Khi (Figure 1). However, when the present innovative method is used, PPV and SVV should be sampled during the same period of time.

In conclusion, we believe that dynamic Ea predicting arterial pressure response to volume loading in preloaddependent patients is an interesting physiological concept. However, this demonstration cannot be achieved without taking into consideration the impact of PPV/ SVV sampling.

\section{Abbreviations}

$\mathrm{AP}$, arterial pressure; Ea, arterial elastance; PP, pulse pressure; PPV, pulse pressure variation; SV, stroke volume; SW, stroke volume variation.

Competing interests

The authors declare that they have no competing interests.

Published: 23 March 2011

\section{References}

1. Monge Garcia MI, Gil Cano A, Gracia Romero M: Dynamic arterial elastance to predict arterial pressure response to volume loading in preloaddependent patients. Crit Care 2011, 15:R15.

2. Bendjelid K: When to recalibrate the PiCCO? From a physiological point of view, the answer is simple. Acta Anaesthesiol Scand 2009, 53:689-690.

3. Manecke GR: Edwards FloTrac sensor and Vigileo monitor: easy, accurate, reliable cardiac output assessment using the arterial pulse wave. Expert Rev Med Devices 2005, 2:523-527.

4. Michard F, Chemla D, Richard C, Wysocki M, Pinsky MR, Lecarpentier Y, Teboul $J L:$ Clinical use of respiratory changes in arterial pulse pressure to monitor the hemodynamic effects of PEEP. Am J Respir Crit Care Med 1999, 159:935-939.

doi:10.1186/cc10088

Cite this article as: Giraud $R$, et al:. Pulse pressure variation, stroke volume variation and dynamic arterial elastance. Critical Care 2011, 15:414.
${ }^{*}$ Correspondence: Karim.Bendjelid@hcuge.ch

Medecin Adjoint Agrégé, Division des Soins Intensifs, Hôpitaux Universitaires de Genève, $\mathrm{CH}-1211$ Genève 14, Switzerland 


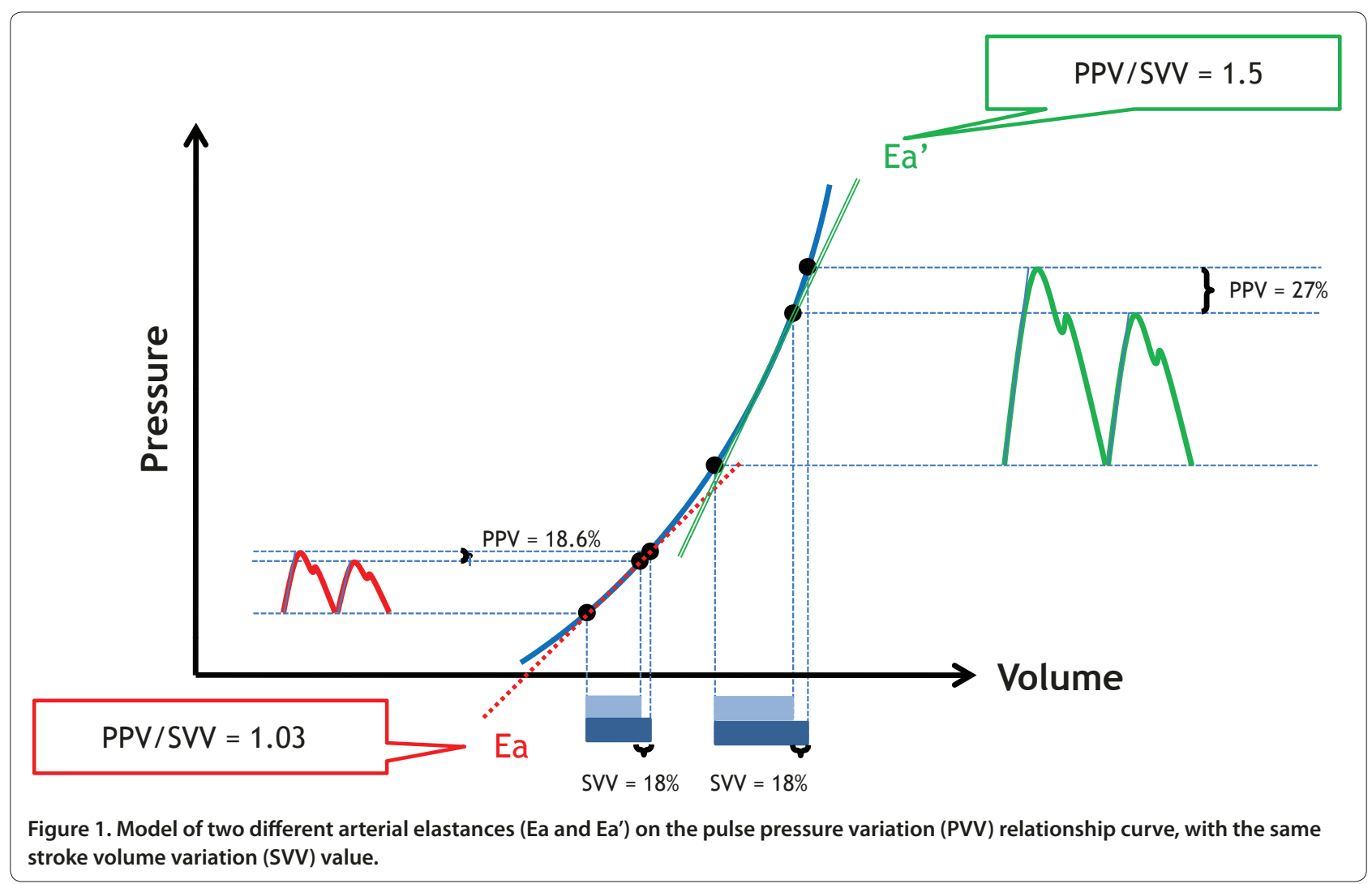

